\title{
Fever, Sweat, and Hot Flashes
}

National Cancer Institute

\section{Source}

National Cancer Institute. Fever, Sweat, and Hot Flashes. NCI Thesaurus. Code C115213.

Temperature elevation, sweating, and red flushed face. 